\title{
Critical Temperatures, Pressures, and Volumes of Hydrogen, Deuterium, and Hydrogen Deuteride
}

\author{
Harold J. Hoge ${ }^{1}$ and James W. Lassiter ${ }^{2}$
}

\begin{abstract}
The critical temperatures, pressures, and volumes of $\mathrm{H}_{2}, \mathrm{HD}$, and $\mathrm{D}_{2}$ have been determined by measuring short sections of $P-V$ isotherms in the neighborhood of the critical points. The $\mathrm{H}_{2}$ and $\mathrm{D}_{2}$ samples were catalyzed to ortho-para equilibrium at $20.4^{\circ} \mathrm{K}$ and are designated $\mathrm{e}-\mathrm{H}_{2}$ and $\mathrm{e}-\mathrm{D}_{2}$. For $\mathrm{e}-\mathrm{H}_{2}$ the values found are $T_{c}=32.9_{94}{ }^{\circ} \mathrm{K}, P_{c}=12.7_{70}$ atm, and $T_{c}=65.5 \mathrm{~cm}^{3}$ mole $^{-1}$. For HD the corresponding values are $35.90{ }^{\circ} \mathrm{K}, 14.6_{45} \mathrm{~atm}$, and $62.8 \mathrm{~cm}^{3} \mathrm{~mole}^{-1}$; for $\mathrm{e}-\mathrm{D}_{2}$ the values are $38.2_{62}{ }^{\circ} \mathrm{K}, 16.2_{82} \mathrm{~atm}$, and $60.3 \mathrm{~cm}^{3} \mathrm{~mole}^{-1}$. A method of correlating isotherm data for different substances, based on the use of graphs of $\log P$ versus $\log T$, is described.
\end{abstract}

\section{Introduction}

The present paper and the accompanying one on vapor pressures and dew-point pressures $[1]^{3}$ comprise a full report of a program of determination of properties of the hydrogens undertaken at the National Bureau of Standards early in 1950. The situation with regard to critical data at that time was very similar to the situation with regard to vapor pressures above $1 \mathrm{~atm}$; the field having been neglected from the time of the last Leiden measurements [2] in 1917, until very recently, when White, Friedman, and Johnston [3] published critical data for normal hydrogen, and a preliminary report [4] was made of the present work.

\section{Experimental Methods}

The measurements were made with an apparatus used previously in an investigation of the vapor pressure of oxygen [5]. Minor modifications are mentioned in [1]. Pressure exerted by the hydrogen in the equilibrium chamber was transmitted out of the cryostat through a small metal tube that connected to one end of a $U$-tube of stainless steel $(1 / 2-i n$. outside diameter). The lower-part of the U-tube contained mercury, and the arm not filled with hydrogen contained water through which the pressure was transmitted to oil and thence to the piston gage with which pressures were measured. By means of a pump, water could be forced into or removed from the line. This caused the mercury to rise in one side of the $U$-tube and to fall in the other, thus varying the space available for hydrogen in the U-tube and causing material to flow into or out of the equilibrium chamber. This made it possible to measure the sample in the equilibrium chamber at different molar volumes.

The experimental data are given in tables 1, 2, and 3. All observations are numbered in chronological order, with the run number preceding the

Present address: Leeds \& Northrup Company, Phila., Pa.

2 Present address: U. S. Coast Guard, Cape May, N. J.

3 Figures in brackets indicate the literature references at the end of this paper. decimal point. The directly observed (unadjusted) values of temperature and pressure are given in columns 2 and 3 of each table. Temperature variation among the points of a given isotherm was small; nonetheless, corrections were made to bring each group to a common temperature. This was accomplished by using appropriate values of $(1 / P)(d P / d T)$ obtained whenever possible from tables 5, 6, and 7 of [1], which give $\log P$ as a function of $1 / T$. Above the range of these tables, estimated values of $(1 / P)(d P / d T)$ were used. The correction is exact only where two phases are present in the equilibrium chamber, but fortunately this is the place where the corrections are most important. Adjusted values of $T$ and $P$ are given in columns 4 and 5 of the tables. The adjustments seldom changed the pressure by more than $1 \mathrm{~mm} \mathrm{Hg}$.

The molar volume corresponding to each observation is the effective volume of the equilibrium chamber divided by the number of moles of hydrogen present in it when the observation was made. This quantity, $V$, is given in column 6 of the tables. The effective volume of the equilibrium chamber and the volumes of the various parts of the pressure-transmitting line were determined in a separate series of experiments. The number of moles of sample confined in the equilibrium chamber and in the pressure-transmitting line, including the U-tube, was determined separately for each run. For each observation of a given run, the number of moles not in the equilibrium chamber was computed by means of the gas laws, and subtracted from the total number to give the quantity actually inside the chamber.

All the necessary knowledge of volumes may be obtained after the apparatus is assembled, provided the inside diameter of the U-tube is known.

If $n$ moles of gas are confined in a volume $V_{1}$ at temperature $T_{1}$, they satisfy the equation $P V_{1}=$ $n R T_{1} Z_{1}$, where the compressibility factor $Z$ accounts for the deviation of the gas from ideality. If the volume containing the gas is not all at uniform temperature it must be divided into subvolumes. The number of moles of gas in the $i$ th subvolume is 
TABLE 1. Isotherms of $\mathrm{e}-\mathrm{H}_{2}$

Observations of the dependence of pressure on volume in the critical region

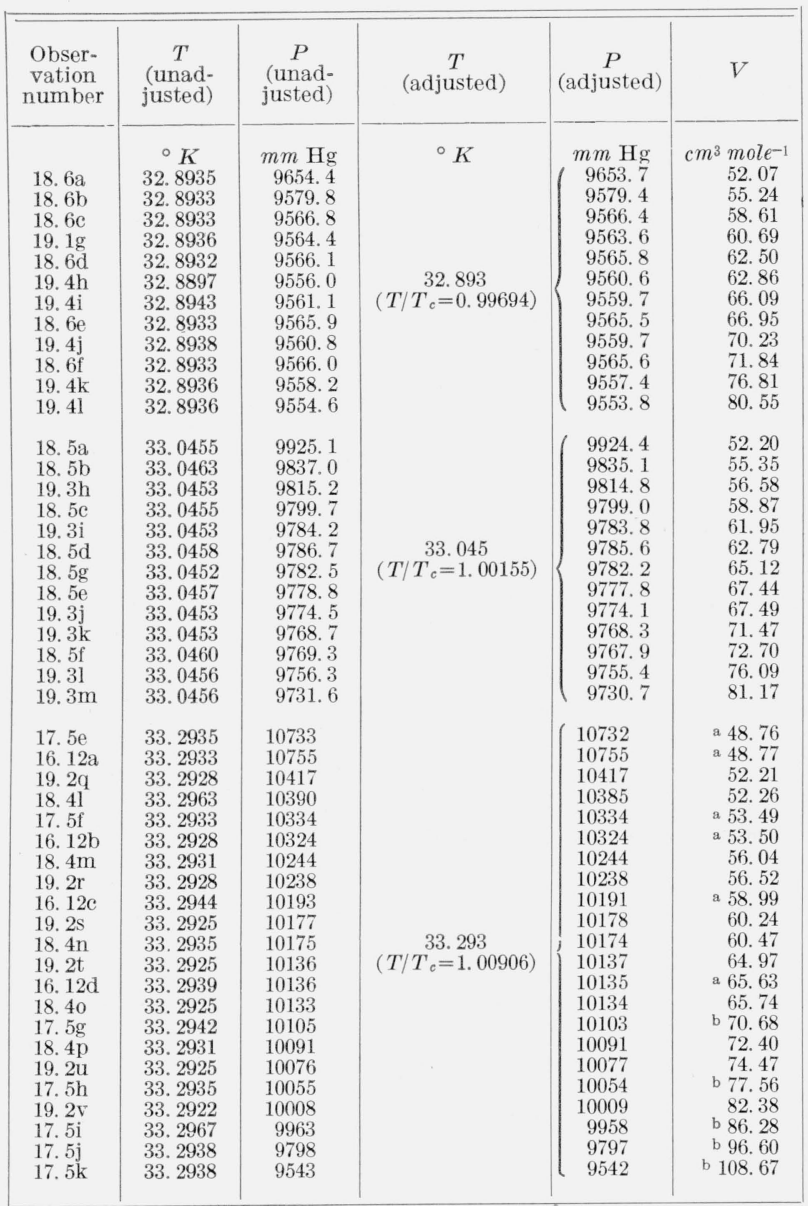

a, b No measurements of mass of material were made corresponding to the two groups of observations marked respectively by a and $b$. Masses were determined as described in the text, from the superposition of graphs.

given by $n_{i} R=P V_{i} / T_{i} Z_{i}$, and summing over all subvolumes

$$
n R=R \sum_{i} n_{i}=P \sum_{i}\left(V_{i} / T_{i} Z_{i}\right)
$$

With all the volumes $V_{i}$ at the same known temperature (room temperature), and with enough gas in the apparatus to obtain convenient pressures, the position of the mercury meniscus in the U-tube was varied and the resulting changes in $P$ observed. In this way the total volume occupied by the sample was found to be

$$
\sum_{i} V_{i}\left(\mathrm{~cm}^{3}\right)=84.66-0.0968 h_{1}
$$

where $h_{1}$ was the scale reading in millimeters of the mercury meniscus in the arm of the U-tube containing hydrogen. Previously, when the apparatus had been used to measure the vapor pressure of oxygen [5], similar measurements had given 84.45 for the constant term. The agreement is considered satisfactory. Having obtained eq 2, the effective
TABLE 2. Isotherms of $\mathrm{HD}$

\begin{tabular}{|c|c|c|c|c|c|}
\hline $\begin{array}{l}\text { Obser- } \\
\text { vation } \\
\text { number }\end{array}$ & $\begin{array}{c}T \\
\text { (unad- } \\
\text { justed) }\end{array}$ & $\begin{array}{c}P \\
\text { (unad- } \\
\text { justed) }\end{array}$ & $\begin{array}{c}T \\
\text { (adjusted) }\end{array}$ & $\underset{\text { (adjusted) }}{P}$ & $V$ \\
\hline $\begin{array}{l}3.16 \mathrm{~b} \\
3.16 \mathrm{c} \\
3.16 \mathrm{a} \\
3.16 \mathrm{~d} \\
3.16 \mathrm{e}\end{array}$ & $\begin{array}{c}\circ K \\
35.033 \\
35.033 \\
35.033 \\
35.034 \\
35.034\end{array}$ & $\begin{array}{l}m m \mathrm{Hg} \\
9844 \\
9841 \\
9841 \\
9843 \\
9841\end{array}$ & $\begin{array}{c}{ }^{\circ} K \\
35.033 \\
\left(T / T_{c}=0.97563\right)\end{array}$ & $\left\{\begin{array}{c}m m \mathrm{Hg} \\
9844 \\
9841 \\
9841 \\
9842 \\
9840\end{array}\right.$ & $\begin{array}{c}\mathrm{cm}^{3} \text { mole }{ }^{-1} \\
59.48 \\
63.60 \\
68.10 \\
73.23 \\
81.75\end{array}$ \\
\hline $\begin{array}{l}\text { 5. } 2 \mathrm{~h} \\
5.2 \mathrm{~g} \\
5.2 \mathrm{f} \\
5.2 \mathrm{~d} \\
5.2 \mathrm{e} \\
5.2 \mathrm{c} \\
5.2 \mathrm{~b} \\
5.2 \mathrm{a}\end{array}$ & $\begin{array}{l}\text { 35. } 7499 \\
\text { 35. } 7494 \\
\text { 35. } 7494 \\
\text { 35. } 7486 \\
\text { 35. } 7496 \\
\text { 35. } 7487 \\
\text { 35. } 7486 \\
\text { 35. } 7491\end{array}$ & $\begin{array}{l}10889 \\
10886 \\
10889 \\
10887 \\
10885 \\
10886 \\
10880 \\
10860\end{array}$ & $\begin{array}{c}35.749 \\
\left(T / T_{c}=0.99557\right)\end{array}$ & $\left\{\begin{array}{l}10888 \\
10885 \\
10888 \\
10888 \\
10884 \\
10886 \\
10881 \\
10860\end{array}\right.$ & $\begin{array}{l}57.76 \\
60.91 \\
64.12 \\
67.68 \\
67.84 \\
72.11 \\
75.72 \\
82.59\end{array}$ \\
\hline $\begin{array}{l}5.3 \mathrm{a} \\
5.3 \mathrm{~b} \\
5.3 \mathrm{c} \\
5.3 \mathrm{~d} \\
5.3 \mathrm{e} \\
5.3 \mathrm{f} \\
5.3 \mathrm{~g}\end{array}$ & $\begin{array}{l}35.8798 \\
35.8796 \\
35.8798 \\
35.8796 \\
35.8795 \\
35.8795 \\
35.8793\end{array}$ & $\begin{array}{l}11095 \\
11091 \\
11089 \\
11091 \\
11078 \\
11056 \\
11021\end{array}$ & $\begin{array}{c}35.880 \\
\left(T / T_{c}=0.99922\right)\end{array}$ & $\begin{array}{l}11095 \\
11092 \\
11089 \\
11092 \\
11079 \\
11057 \\
11022\end{array}$ & $\begin{array}{l}57.83 \\
61.04 \\
64.68 \\
69.36 \\
74.15 \\
78.75 \\
82.68\end{array}$ \\
\hline $\begin{array}{l}3.17 \mathrm{~d} \\
3.17 \mathrm{e} \\
3.17 \mathrm{c} \\
3.17 \mathrm{~b} \\
3.17 \mathrm{a}\end{array}$ & $\begin{array}{l}36.022 \\
36.023 \\
36.023 \\
36.023 \\
36.023\end{array}$ & $\begin{array}{l}11319 \\
11308 \\
11298 \\
11257 \\
11132\end{array}$ & $\begin{array}{c}36.023 \\
\left(T / T_{c}=1.00320\right)\end{array}$ & $\begin{array}{l}11321 \\
11308 \\
11298 \\
11257 \\
11132\end{array}$ & $\begin{array}{l}59.86 \\
63.22 \\
66.89 \\
75.71 \\
86.76\end{array}$ \\
\hline $\begin{array}{l}4.10 \mathrm{~b} \\
4.10 \mathrm{c} \\
4.10 \mathrm{a} \\
4.10 \mathrm{~d} \\
4.10 \mathrm{e} \\
4.10 \mathrm{f} \\
4.10 \mathrm{~g} \\
4.10 \mathrm{~h}\end{array}$ & $\begin{array}{l}36.250 \\
36.251 \\
36.251 \\
36.250 \\
36.250 \\
36.249 \\
36.249 \\
36.249\end{array}$ & $\begin{array}{l}11715 \\
11684 \\
11648 \\
11626 \\
11603 \\
11565 \\
11508 \\
11427\end{array}$ & $\begin{array}{c}36.250 \\
\left(T / T_{c}=1.00952\right)\end{array}$ & $\left\{\begin{array}{l}11715 \\
11682 \\
11646 \\
11626 \\
11603 \\
11567 \\
11510 \\
11429\end{array}\right.$ & $\begin{array}{l}57.88 \\
60.84 \\
65.15 \\
67.87 \\
70.61 \\
74.39 \\
79.05 \\
84.35\end{array}$ \\
\hline
\end{tabular}

Observations of the dependence of pressure on volume in the critical region

volume of the cryostat was determined by noting the pressure, first with all volumes at room temperature, and again after cooling the cryostat with liquid air, and applying eq 1 to the results. The volume was found to be $5.88 \mathrm{~cm}^{3}$.

Once the volumes were known, the number of moles of gas confined could be determined from any set of pressure and temperature readings, provided none of the sample was condensed. Normally, such a determination was made at the completion of each run, after the crvostat had warmed to liquid-air temperature and the pressure had risen to 25 to 35 atm. The molar volume $V$ corresponding to each individual observation of the run could then be computed by summing eq 1 over all volumes except that of the cryostat itself, and subtracting the result from the total number of moles in the system. The temperature of the U-tube was indicated by a mercury-in-glass thermometer. The table of $Z$-values given by Woolley, Scott, and Brickwedde [6] was used for all three gases. The table is for $H_{2}$, but was considered adequate for $\mathrm{HD}$ and $\mathrm{D}_{2}$ also, in view of the fact that other quantities involved in the calculation were not known with very high accuracy.

In two instances we failed to make any measurement of the total mass of sample in the system. The two groups of observations involved are for the highest isotherm of e- $\mathrm{H}_{2}$ and are indicated in table 1 . Calculations of the molar volume were made for these observations in the usual way, except that the unknown total number of moles appeared as an arbitrary constant. Graphs of pressure versus 
TABLE 3. Isotherms of $\mathrm{e}-\mathrm{D}_{2}$

Observations of the dependence of pressure on volume in the critical region

\begin{tabular}{|c|c|c|c|c|c|}
\hline $\begin{array}{l}\text { Obser- } \\
\text { vation } \\
\text { number }\end{array}$ & $\begin{array}{c}T \\
\text { (unad- } \\
\text { justed) }\end{array}$ & $\begin{array}{c}P \\
\text { (unad- } \\
\text { justed) }\end{array}$ & $\begin{array}{c}T \\
\text { (adjusted) }\end{array}$ & $\begin{array}{c}P \\
\text { (adjusted) }\end{array}$ & $V$ \\
\hline $\begin{array}{l}\text { 6. } 21 \mathrm{c} \\
6.21 \mathrm{a} \\
6.21 \mathrm{~b}\end{array}$ & $\begin{array}{c}\circ K \\
37.1983 \\
37.1988 \\
37.1991\end{array}$ & $\begin{array}{c}m m \mathrm{Hg} \\
10708 \\
10709 \\
10708\end{array}$ & $\begin{array}{c}{ }^{\circ} K \\
37.199 \\
\left(T / T_{c}=0.97222\right)\end{array}$ & $\left\{\begin{array}{c}m m \mathrm{Hg} \\
10709 \\
10709 \\
10708\end{array}\right.$ & $\begin{array}{l}c m^{3} \text { mole } e^{-1} \\
\quad 63.74 \\
70.60 \\
80.73\end{array}$ \\
\hline $\begin{array}{l}7.4 \mathrm{a} \\
7.4 \mathrm{~b} \\
8.6 \mathrm{a} \\
8.6 \mathrm{~b} \\
6.22 \mathrm{c} \\
6.22 \mathrm{a} \\
6.22 \mathrm{~b}\end{array}$ & $\begin{array}{l}38.2029 \\
38.2036 \\
38.2038 \\
38.2031 \\
38.2017 \\
38.2022 \\
38.2018\end{array}$ & $\begin{array}{l}13969 \\
12292 \\
12276 \\
12272 \\
12274 \\
12272 \\
12163\end{array}$ & $\begin{array}{c}38.203 \\
\left(T / T_{c}=0.99846\right)\end{array}$ & $\begin{array}{l}13969 \\
12291 \\
12275 \\
12272 \\
12276 \\
12273 \\
12165\end{array}$ & $\begin{array}{l}40.19 \\
52.48 \\
56.44 \\
63.04 \\
64.20 \\
72.35 \\
84.13\end{array}$ \\
\hline $\begin{array}{l}8.7 \mathrm{a} \\
8.7 \mathrm{~b} \\
8.7 \mathrm{c} \\
8.7 \mathrm{~d} \\
8.7 \mathrm{e} \\
8.7 \mathrm{f}\end{array}$ & $\begin{array}{l}38.3978 \\
38.3979 \\
38.3978 \\
38.3977 \\
38.3977 \\
38.3977\end{array}$ & $\begin{array}{l}12630 \\
12610 \\
12599 \\
12588 \\
12570 \\
12536\end{array}$ & $\begin{array}{c}38.398 \\
\left(T / T_{c}=1.00355\right)\end{array}$ & $\begin{array}{l}12630 \\
12610 \\
12599 \\
12588 \\
12570 \\
12536\end{array}$ & $\begin{array}{l}54.12 \\
57.15 \\
60.49 \\
64.25 \\
68.57 \\
73.34\end{array}$ \\
\hline $\begin{array}{l}7.5 \mathrm{a} \\
7.5 \mathrm{~b} \\
7.5 \mathrm{c} \\
7.5 \mathrm{~d} \\
7.5 \mathrm{e} \\
8.4 \mathrm{a} \\
7.5 \mathrm{f} \\
7.5 \mathrm{~g} \\
8.4 \mathrm{~b} \\
8.4 \mathrm{c} \\
8.4 \mathrm{~d} \\
8.4 \mathrm{e}\end{array}$ & $\begin{array}{l}38.5556 \\
38.5552 \\
38.5554 \\
38.5558 \\
38.5554 \\
38.5563 \\
38.5556 \\
38.5554 \\
38.5566 \\
38.5566 \\
38.5565 \\
38.5563\end{array}$ & $\begin{array}{l}15010 \\
14236 \\
13654 \\
13295 \\
13106 \\
13003 \\
12991 \\
12952 \\
12907 \\
12866 \\
12827 \\
12742\end{array}$ & $\begin{array}{c}38.556 \\
\left(T / T_{c}=1.00768\right)\end{array}$ & $\begin{array}{l}15011 \\
14237 \\
13655 \\
13295 \\
13107 \\
13002 \\
12992 \\
12953 \\
12906 \\
12865 \\
12826 \\
12742\end{array}$ & $\begin{array}{l}40.30 \\
42.20 \\
44.33 \\
46.58 \\
48.94 \\
50.74 \\
51.85 \\
53.46 \\
55.57 \\
60.28 \\
65.72 \\
73.99\end{array}$ \\
\hline $\begin{array}{l}7.6 \mathrm{a} \\
7.6 \mathrm{~b} \\
7.6 \mathrm{c} \\
7.6 \mathrm{~d} \\
7.6 \mathrm{e} \\
8.5 \mathrm{a} \\
7.6 \mathrm{f} \\
7.6 \mathrm{~g} \\
8.5 \mathrm{~b} \\
8.5 \mathrm{c} \\
8.5 \mathrm{~d} \\
8.5 \mathrm{e}\end{array}$ & $\begin{array}{l}38.8794 \\
38.8766 \\
38.8795 \\
38.8794 \\
38.8794 \\
38.8801 \\
38.8794 \\
38.8791 \\
38.8807 \\
38.8801 \\
38.8801 \\
38.8806\end{array}$ & $\begin{array}{l}15981 \\
15075 \\
14421 \\
14017 \\
13775 \\
13666 \\
13608 \\
13545 \\
13492 \\
13399 \\
13312 \\
13155\end{array}$ & $\begin{array}{c}38.880 \\
\left(T / T_{c}=1.01615\right)\end{array}$ & $\begin{array}{l}15982 \\
15082 \\
14422 \\
14018 \\
13776 \\
13666 \\
13609 \\
13547 \\
13491 \\
13399 \\
13312 \\
13154\end{array}$ & $\begin{array}{l}40.37 \\
42.40 \\
44.67 \\
47.05 \\
49.53 \\
50.86 \\
52.66 \\
54.50 \\
55.91 \\
60.87 \\
66.54 \\
75.23\end{array}$ \\
\hline $\begin{array}{l}7.7 \mathrm{a} \\
7.7 \mathrm{~b} \\
7.7 \mathrm{c} \\
6.23 \mathrm{c} \\
6.23 \mathrm{a} \\
6.23 \mathrm{~b}\end{array}$ & $\begin{array}{l}39.1990 \\
39.1985 \\
39.1988 \\
39.1981 \\
39.1995 \\
39.1980\end{array}$ & $\begin{array}{l}16937 \\
15878 \\
14113 \\
13839 \\
13627 \\
13211\end{array}$ & $\begin{array}{c}39.199 \\
\left(T / T_{c}=1.02449\right)\end{array}$ & $\begin{array}{l}16937 \\
15879 \\
14113 \\
13841 \\
13626 \\
13213\end{array}$ & $\begin{array}{l}40.45 \\
42.58 \\
55.40 \\
64.74 \\
73.54 \\
87.00\end{array}$ \\
\hline $\begin{array}{l}6.24 \mathrm{a} \\
6.24 \mathrm{~b}\end{array}$ & $\begin{array}{l}40.1960 \\
40.1959\end{array}$ & $\begin{array}{l}14876 \\
14151\end{array}$ & $\begin{array}{c}40.196 \\
\left(T / T_{c}=1.05055\right)\end{array}$ & $\left\{\begin{array}{l}14876 \\
14151\end{array}\right.$ & $\begin{array}{l}74.98 \\
89.63\end{array}$ \\
\hline $\begin{array}{l}6.25 \mathrm{a} \\
6.25 \mathrm{~b}\end{array}$ & $\begin{array}{l}41.2076 \\
41.2085\end{array}$ & $\begin{array}{l}16066 \\
15020\end{array}$ & $\begin{array}{c}41.208 \\
\left(T / T_{c}=1.07700\right)\end{array}$ & $\left\{\begin{array}{l}16067 \\
15019\end{array}\right.$ & $\begin{array}{l}76.42 \\
92.33\end{array}$ \\
\hline
\end{tabular}

number of moles of hydrogen in the equilibrium chamber were made on transparent paper for these data (with the zero of abscissas undetermined); and a similar graph was made of the rest of the data of the isotherm, for which the zero of abscissas was known. The graphs of the "unknown" data were superposed in turn on the graph of the "known" data, and moved along the axis of abscissas until known and unknown graphs merged into a single continuous curve. By comparing the two abscissa scales the total number of moles of sample employed in each unknown run was determined.

\section{Analysis of the Data}

The preliminary analysis of the isotherms was carried out in the usual way by plotting $P$ versus $V$ for each modification of hydrogen, drawing in the liquid-vapor domes, and taking the highest point of each dome as the critical point of that particular modification. It was difficult to determine the positions of the domes with the desired accuracy, however, so we sought some method of correlating the data for the three kinds of hydrogen in order to obtain more accurate critical constants for all. If the critical temperature and pressure of each variety were known, $P / P_{c}$ could be plotted versus $V / V_{c}$ with all three modifications on the same graph; and, if the law of corresponding stateswere obeyed all the isotherms would form a single family. Since only approximate values of $P_{c}$ and $V_{c}$ were available, this method of correlation could be used only by a process of successive approximations. However, it was recognized that this difficulty could be avoided by taking logarithms. If log $\left(P / P_{c}\right)$ were plotted versus $\log \left(V / V_{c}\right)$, the isotherms of the three modifications would, of course, form a single family just as they would when the variables were $P / P_{c}$ and $V / V_{c}$. But a graph of $\log \left(P / P_{c}\right)$ versus $\log \left(V / V_{c}\right)$ differs from a graph of $\log P$ versus $\log V$ only by a translation of $-\log P_{c}$ along the axis of ordinates and of $-\log V_{c}$ along the axis of abscissas. Hence, if separate graphs of $\log P$ versus $\log V$ for each modification are prepared on transparent stock, it should be possible to superpose them in such a way as to form a single family of isotherms, to draw a single liquid-vapor dome for the family, and thus to obtain critical constants for the three modifications with improved absolute accuracy and much greater relative accuracy than could otherwise be obtained.

The result of applying this type of correlation is shown in figure 1 . The three sets of data were initially plotted on three separate sheets of tracing cloth and superposed for viewing by transmitted light. The graphs were shifted relative to each other along the axes of coordinates until they most nearly blended into a single family. The relation between the various coordinate scales was then noted and all the data plotted on a single sheet. On this graph the liquid-vapor dome was drawn and the critical point selected. The coordinates of this point with respect to the three original graphs give $\log P_{c}$ and $\log V_{c}$ for the three modifications of hydrogen. The corresponding critical temperatures were found by substituting each value of $P_{c}$ into the appropriate vapor-pressure table (table 5,6 , or 7) of [1]. The critical constants are given in table 4. Values of the compressibility factor $Z=P V / n R T$ at the critical point are included. After the critical constants had been determined, $T / T_{c}$ was computed for each isotherm of figure 1, and coordinate scales in terms of $\log \left(P / P_{c}\right)$ and $\log$ $\left(V / V_{c}\right)$ were substituted for those originally used, so that the same scales could be used for all three modifications.

TABLE 4. Critical constants of $\mathrm{e}-\mathrm{H}_{2}, \mathrm{HD}$, and $\mathrm{e}-\mathrm{D}_{2}$

\begin{tabular}{|c|c|c|c|c|c|c|}
\hline \multirow[b]{2}{*}{$\begin{array}{l}\mathrm{e}-\mathrm{H}_{2} \\
\mathrm{HD} \\
\mathrm{e}-\mathrm{D}_{2}\end{array}$} & $T_{c}$ & \multicolumn{3}{|c|}{$P_{c}$} & $V_{c}$ & $P_{c} V_{\mathrm{c}} / R T_{\mathrm{c}}$ \\
\hline & $\begin{array}{c}{ }^{\circ} K \\
32.994 \\
35.903 \\
33.262\end{array}$ & $\begin{array}{c}m m \mathrm{Hg} \\
9,705 \\
11,130 \\
12,374\end{array}$ & $\begin{array}{c}\text { atm } \\
12.770 \\
14.645 \\
16.282\end{array}$ & $\begin{array}{c}\text { psia } \\
187.67 \\
215.22 \\
239.27\end{array}$ & $\begin{array}{c}\mathrm{cm}^{3} \mathrm{~mole}^{-1} \\
65.5 \\
62.8 \\
60.3\end{array}$ & $\begin{array}{r}0.309 \\
.312 \\
.312\end{array}$ \\
\hline
\end{tabular}




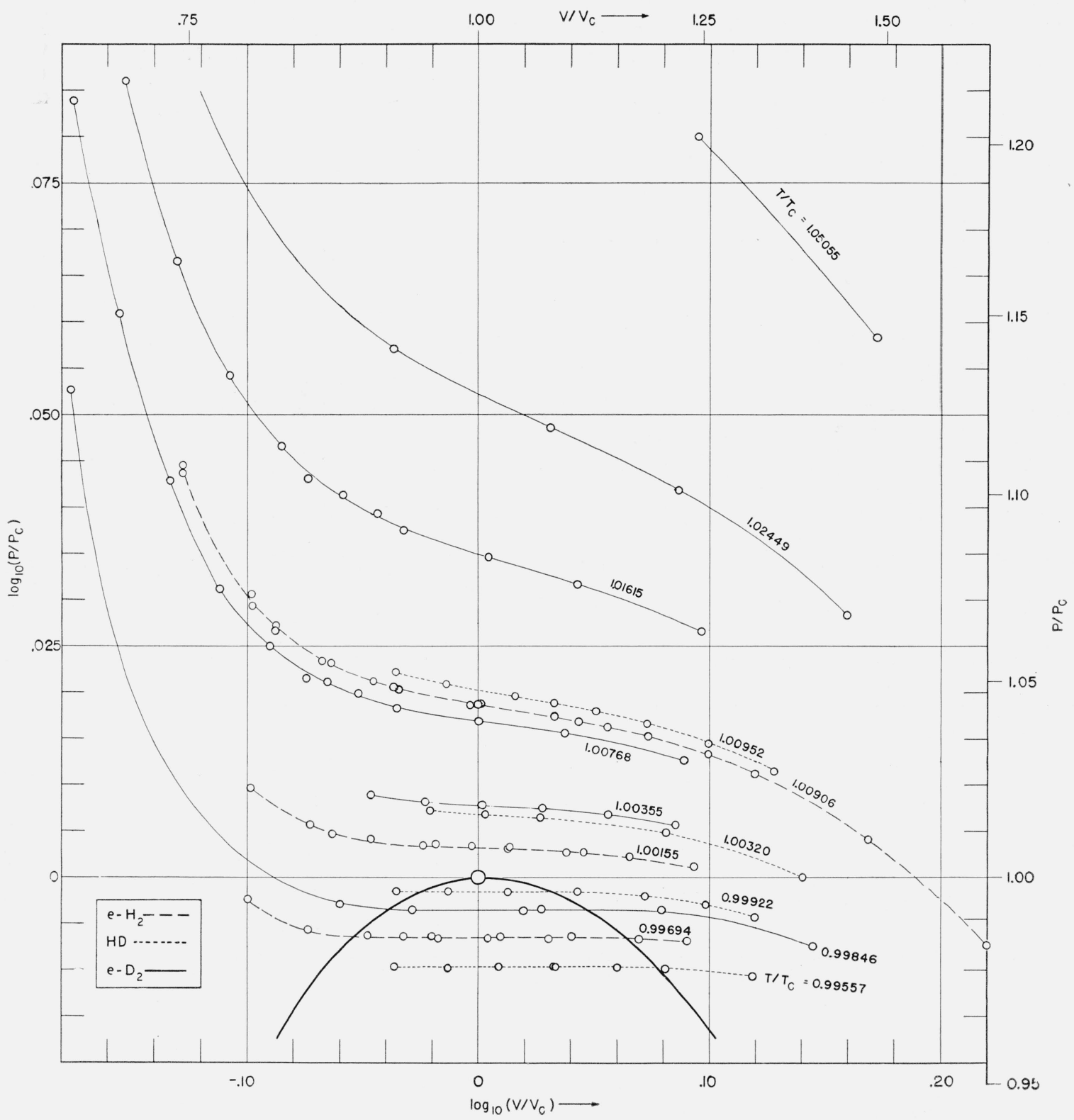

FIGURE 1. Isotherms of $\mathrm{e}-\mathrm{H}_{2}, \mathrm{HD}$, and $\mathrm{e}-\mathrm{D}_{2}$ in the neighborhood of the critical point.

To help in properly drawing the liquid-vapor dome, several other sets of isotherm data were plotted on $\log P$ versus $\log T$ graphs and compared with our own results by superposition. The data plotted included those of Michels, Blaisse, and Michels for $\mathrm{CO}_{2}$ [7], and those of Onnes, Crommelin, and Cath for hydrogen [2]. The isotherm data in the latter paper are given graphically rather than numerically, so the coordinates of the plotted points and of various points on the dome had to be read from the published graph. The dome drawn in figure 1 is in agreement with that of the Leiden observers within the accuracy of the observations. The $\mathrm{CO}_{2}$ data could not be satisfactorily superposed on our hydrogen data because the dome was too wide. It was estimated that if for $\mathrm{CO}_{2}$ one should plot $\log P$ versus $0.81 \log T$, the resulting graph could be superposed satisfactorily on the hydrogen graph. The difference in dome-shape of hydrogen and $\mathrm{CO}_{2}$ is undoubtedly real. It would be interesting to compare the critical regions of other triatomic molecules, such as $\mathrm{N}_{2} \mathrm{O}$ and $\mathrm{SO}_{2}$ with that of $\mathrm{CO}_{2}$, to see the extent to which triatomic molecules follow one law of corresponding states and diatomic molecules another.

The vapor-pressure tables of [1] are believed to be accurate near the critical point to $\pm 8 \mathrm{~mm} \mathrm{Hg}$ in the case of $\mathrm{e}-\mathrm{H}_{2}$ and $\mathrm{e}-\mathrm{D}_{2}$, and to $\pm 15 \mathrm{~mm} \mathrm{Hg}$ in the case of HD. The uncertainties of the critical constants are greater than these values, however, because they include the additional uncertainty in locating the proper spot on figure 1 to choose as the 
critical point. It is estimated that the critical point selected is uncertain by $\pm 0.001 \mathrm{in} \log \left(P / P_{\mathrm{c}}\right)$. This is equivalent to $\pm 22 \mathrm{~mm} \mathrm{Hg}$ for $\mathrm{e}-\mathrm{H}_{2}, \pm 26 \mathrm{~mm} \mathrm{Hg}$ for $\mathrm{HD}$, and $\pm 28 \mathrm{~mm} \mathrm{Hg}$ for e- $\mathrm{D}_{2}$. To these may be added the estimated uncertainties in the vaporpressure tables, giving (after rounding off) $\pm 30 \mathrm{~mm}$ $\mathrm{Hg}$ for $\mathrm{e}-\mathrm{H}_{2}, \pm 40 \mathrm{~mm} \mathrm{Hg}$ for $\mathrm{HD}$, and $\pm 35 \mathrm{~mm} \mathrm{Hg}$ for e- $\mathrm{D}_{2}$. Using values of $d P / d T$ from the accepted vapor-pressure tables of [1], these uncertainties are approximately equivalent to \pm 20 mdeg for $\mathrm{e}-\mathrm{H}_{2}$ and $\mathrm{e}-\mathrm{D}_{2}$, and to \pm 25 mdeg for HD. An additional allowance of \pm 20 mdeg must be made for uncertainty in the temperature scale.

The position of the critical point in figure 1 is uncertain by perhaps \pm 0.005 in $\log \left(V^{*} / V_{c}\right)$, which is equivalent to slightly more than 1 percent in $V$. Errors in determining the volumes of the equilibrium chamber and the various parts of the pressuretransmitting line are not included in this figure. These would affect the determinations of the total mass of material employed in each run, and would introduce a systematic error into $\log \left(T / T_{c}\right)$. An uncertainty of \pm 2 percent is thought to be adequate to cover errors due to all causes. The relative errors of the critical volumes of the three varieties are much smaller than the total errors. This type of error may be estimated from the accuracy with which the three original $\log P-\log V$ graphs could be correctly superposed. It is estimated that the ratio of any two critical volumes is correct to 5 per mille. The relative accuracy of any two critical pressures is probably 1 per mille, and that of any two critical temperatures about 3 parts in 10,000 .

The published critical data for hydrogen were summarized by Pickering [8] in 1926. He selected as best values: $t_{c}=-239.9^{\circ} \mathrm{C}, P_{c}=12.8 \mathrm{~atm}$, and $\rho_{c}=0.0310 \mathrm{~g} \quad \mathrm{~cm}^{-3}$ (equivalent to $T_{c}=65.0 \mathrm{~cm}^{3}$ mole $\left.{ }^{-1}\right)$. These are essentially the values of Onnes, Crommelin, and Cath [2] for the critical temperature and pressure and that of Mathias, Crommelin, and Onnes [9], for the critical density. In [2] the critical temperature is given both in centigrade and in Kelvin units $\left(-239.91^{\circ} \mathrm{C}=33.18^{\circ} \mathrm{K}\right)$. Since the Leiden authors were unaware of the necessity of controlling ortho-para compositions, we may assume that they worked with normal (normal $=0.25$ parahydrogen, 0.75 orthohydrogen; see [1]) hydrogen, possibly with an appreciable conversion in the direction of equilibrium hydrogen. In the recent determination of critical constants at Ohio State
University [3], normal hydrogen was also employed, so there are no published data exactly comparable with ours. The Ohio State values are $T_{c}=33.24_{4}{ }^{\circ} \mathrm{K}$, and $P_{c}=12.797 \mathrm{~atm}$.

The above critical points are shown in figure 3 of [1], which is a graph of deviations of observed vapor pressures from an accepted vapor-pressure table. Note that the $\mathrm{n}-\mathrm{H}_{2}$ data in this graph are not to be expected to give zero deviations because the table from which deviations are calculated represents not $\mathrm{n}-\mathrm{H}_{2}$ but $\mathrm{e}-\mathrm{H}_{2}$. To our knowledge there are no previous measurements of the critical constants of $\mathrm{HD}$ and $\mathrm{e}-\mathrm{D}_{2}$ with which our results may be compared.

The valuable assistance of Dino Zei and Raymond A. Nelson in making the measurements is acknowledged.

\section{References}

[1] Harold J. Hoge and Robert D. Arnold, Vapor pressures of hydrogen, deuterium, and hydrogen deuteride and dew-point pressures of their mixtures, J. Research NBS 47, 63 (1951) RP2228.

[2] H. Kamerlingh Onnes, C. A. Crommelin, and P. G. Cath, A preliminary determination of the critical point of hydrogen, Commun. Phys. Lab. Univ. Leiden $151 \mathrm{c}$ (1917).

[3] David White, Abraham Solomon Friedman, and Herrick L. Johnston, The direct determination of the critical temperature and critical pressure of normal hydrogen, J. Am. Chem. Soc. 72,3565 (1950).

[4] Robert D. Arnold and Harold J. Hoge, A test of ideal solution laws for $\mathrm{H}_{2}, \mathrm{HD}$, and $\mathrm{D}_{2}$. Vapor pressures and critical constants of the individual components, J. Chem. Phys. 18, 1295 (1950).

[5] Harold J. Hoge, Vapor pressure and fixed points of oxygen and heat capacity in the critical region, J. Research NBS 44, 321 (1950) RP2081.

[6] Harold W. Woolley, Russell B. Scott, and F. G. Brickwedde, Compilation of thermal properties of hydrogen in its various isotopic and ortho-para modifications, J. Research NBS 41, 379 (1948) RP1932.

[7] A. Michels, B. Blaisse, and C. Michels, The isotherms of $\mathrm{CO}_{2}$ in the neighborhood of the critical point and round the coexistence line, Proc. Roy. Soc. London A160, 358 (1937).

[8] S. F. Pickering, A review of the literature relating to the critical constants of various gases, BS Sci. Pap. 21, 597 (1926) S541.

[9] E. Mathias, C. A. Crommelin, and H. Kamerlingh Onnes, The rectilinear diameter of hydrogen. Commun. Phys. Lab. Univ. Leiden 154b (1921).

Washington, April 27, 1951. 